[Agr. Biol. Chem., Vol. 26, No. 12, p. 824 830, 1962]

\title{
Studies on the Behaviors of Impurities on the Crystallization of L-Glutamic Acid
}

\author{
Part III. Influences of Some Factors on the Solubility \\ By Yoshiki Sakata and Kuniharu Takenouchi \\ Ajinomoto Co., Inc., Kawasaki Factory, Kawasaki \\ Received August 15, 1962
}

\begin{abstract}
The influences of some factors at the both sides of the solid and liquid phases on the solubilities of L-glutamic acid in $a$ and $\beta$-forms in water were examined.

As differences in the conditions of the liquid phase, the effects of co-existing inorganic neutral salts and amino acids on the solubilities were investigated; and as for the inorganic neutral salts applied here, salting-in effects were recognized, the degrees of which were in the following order, i.e., $\mathrm{NH}_{4} \mathrm{Cl}, \quad\left(\mathrm{NH}_{4}\right)_{2} \mathrm{SO}_{4}>\mathrm{KCl}>\mathrm{NaCl}$. The effect in the $\beta$-form was larger than that of in the $a$-form. The influence of co-existing amino acids was very little if the amount was not so much, but the tendency to increase the solubility could be recognized.

As a difference in the condition of the solid phase, the purity of the crystals was picked up, and it was clarified that the crude crystal of L-glutamic acid in $a$-form gave a larger value of the solubility than the purified one.
\end{abstract}

\section{INTRODUCTION}

Solubility is one of the most important factors related to crystallization, and it is essential for the industrial and theoretical purposes to get the precise value of the solubility, upon the investigation of crystallization. As crystallization is usually carried out under co-existence of various impurities, especially in the industrial handling, it is somewhat difficult to get the accurate value of solubility. So is the case of in the preparation of L-glutamic acid, as it is usually isolated from proteineous substances, a plenty of amino acids will co-exist upon the crystallization. Furthermore, as it is most commonly obtained from its salt by neutrallizing the solution with alkali or acid until $\mathrm{pH}$ of the solution reaches to the iso-electric point $(\mathrm{pH}$ $3.2)$, an inorganic neutral salt co-exists in- evitably in the mother liquor. Such co-existing substances in the solution will show some influences on the solubility of L-glutamic acid in water.

Besides such differences in the condition at the side of liquid phase, those of solid phase will also greatly influence on the solubility. One of the authors reported in the other paper $^{1)}$ that two alternative forms of L-glutamic acid have different solubilities in water and they are shown according to the following equations.

$$
\begin{aligned}
& a \text {-form } \log S=-0.377+0.0174 t \\
& \left(t \text { is from } 0^{\circ} \text { to } 30^{\circ} \mathrm{C}\right. \text { ) } \\
& \log S=-0.328+0.0153 t \\
& \left(t \text { is from } 30^{\circ} \text { to } 70^{\circ} \mathrm{C}\right. \text { ) }
\end{aligned}
$$

$\beta$-form $\log S=-0.461+0.0159 t$

Even when two crystals have the same cry-

1) Y. Sakata, This Journal, 25, 835 (1961). 
stal form, some difference in the solubility may be expected, provided that development of the crystal structure differs remarkably, for example in such a case that the solubilities of purified and crude crystals are compared.

In this paper, the influences of amino acids and inorganic salts as co-existing substances on the solubility of L-glutamic acid in water were investigated, and the solubility of the crude crystals of $\mathrm{L}$-glutamic acid in $a$-form was also measured and compared with that of the purified one.

\section{EXPERIMENTAL AND RESULTS}

\section{Influence of Amino Acids.}

\section{Materials.}

L-Glutamic acid in $a$-form. To a solution of $400 \mathrm{~g}$ of commercial mono-sodium I-glutamate monohydrate in about 41 of water (dissolved at room temperature), $2 / 3$ equivalent of $35 \%$ hydrochloric acid was added promptly. To the mixture being stirred for some time, when nucleation of $a$-crystals took place, the rest of hydrochloric acid ( $1 / 3$ equivalent) was added slowly with stirring. The deposited crystals were filtered as soon as the addition of hydrochloric acid was finished. They were washed with water and dried in a vacuum desiccator with sulfuric acid.

$$
\begin{aligned}
\mathrm{N}: & 9.51 \%,[\alpha]_{\mathrm{D}}^{20^{\circ}}:+31.93(2 \mathrm{~N} \mathrm{HCl}) \\
& \beta \text {-form: } 9.5 \% \text { (by X-ray method) }
\end{aligned}
$$

L-Glutamic acid in $\beta$-form. To $28 \%$ aqueous solution of mono-sodium i-glutamate monohydrate, $35 \%$ hydrochloric acid was added slowly at $70^{\circ} \mathrm{C}$; L-glutamic acid in $\beta$-form was crystallized. After the $\mathrm{pH}$ of the solution was adjusted to about 3.2 and the solution was cooled to room temperature under stirring, the crystals were filtered and washed with water and dried in a vacuum desiccator with sulfuric acid.

$$
\begin{aligned}
\mathrm{N}: \quad & 9.51 \%,[\boldsymbol{\alpha}]_{\mathrm{D}}^{20^{\circ}}:+31.95(2 \mathrm{~N} \mathrm{HCl}), \\
& \beta \text {-form: } 100 \%
\end{aligned}
$$

L-alanine, L-lysine monohydrochloride, L-phenylalanine L-histidine monohydrochloride monohydrate

L-lcucine, L-valine

Above materials are commercial reagents of guarantecd grade.

\section{Procedure.}

Into a glass tubc of $50 \mathrm{ml}$ with a spiral stirrer, $30 \mathrm{ml}$ of the aqueous solution of each amino acid, the con- centration of which was in the range from 8 to 15 millimol/dl and the $\mathrm{pH}$ of which was adjusted to 3.2 with hydrochloric acid, was taken. Five grams of L-glutamic acid either in $a$ or $\beta$-form was added to this respectively, and the contents were stirred for $1 \mathrm{hr}$ in a water bath regulated at $25 \pm 0.1^{\circ}$ and $50 \pm 0.1^{\circ} \mathrm{C}$. The concentration of L-glutamic acid in the solution was determined according to the enzymatic method by use of L-glutamic acid decarboxylase.

\section{Result.}

The result of the measurement is shown in Table $\mathbf{I}$.

TABLE I. INFLUENCES OF AMINO ACIDS

$\begin{array}{ccccc}\begin{array}{c}\text { Amino } \\ \text { Acid }\end{array} & \begin{array}{c}\text { Co-existinga) } \\ \text { amount }\end{array} & \text { Temp. } & \begin{array}{c}\text { Solubility } \\ \text { of b) } \\ \alpha \text {-form }\end{array} & \begin{array}{c}\text { Solubility } \\ \text { of b) } \\ \beta \text {-form }\end{array} \\ \text { L-Ala. } & 8.7 & 25^{\circ} \mathrm{G} & 1.14 & 0.87_{5} \\ \text { L-Lys. } & 8.4 & \prime \prime & 1.18 & 0.89_{7} \\ \text { L-Phe. } & 8.8 & \prime \prime & 1.18 & 0.86_{3} \\ \text { L-His. } & 12.6 & \prime \prime & 1.37 & 1.05 \\ \text { L-Leu. } & 7.0 & \prime \prime & 1.14 & 0.86_{2} \\ & 7.6 & 50^{\circ} \mathrm{G} & - & 2.16 \\ & 15.2 & \prime \prime & - & 2.16 \\ \text { L-Val. } & 8.5 & \prime \prime & - & 2.35 \\ \text { none } & - & 25^{\circ} & 1.13_{7} & 0.86_{4} \\ \text { none } & - & 50^{\circ} & - & 2.18_{5} \\ \text { a) millimol/100g water. } & & & \\ \text { 5) } & & & \end{array}$

\section{Influence of Inorganic Neutral Salts. \\ 1. Materials.}

L-Glutamic acid in $a$-form.

L-Glutamic acid in $\beta$-form.

The same materials prepared in I were applied. Ammonium chloride, ammonium sulfate, sodium chloride, potassium chloride: these were all commercial materials of guaranteed grade.

\section{Procedure.}

The solutions of each salt of various concentrations were prepared, and applied to the measurement. The solubilities of L-glutamic acid in $\alpha$ and $\beta$-torms in the salt solutions were measured according to the same procedure as in $\mathbf{I}$, at $30 \pm 0.1^{\circ} \mathrm{C}$. Upon the solubility measurement of the $a$-form, a special attention was paid to the proceeding of the transformation of the saturating body. The concentrations of L-glutamic acid in the $\mathrm{KCl}$ and $\mathrm{NaCl}$ solutions were determined by measuring the total nitrogen according to the Kjeldahl method. In the case of ammonium salts, the determination of L-glutamic acid was carried out ac- 
cording to the enzymatic method, because a considerable large error would be inevitable, when the estimation was tried by the measurements of the total-N and ammonia-N.

\section{Results.}

The results of the measurements are shown in Table II.

\section{Influence of the Purity of the Crystal.}

1. Materials.

TABLE II. INFLUENCE OF INORGANic NeUtral

1. $\mathrm{NaCl}$

$\begin{array}{clcc}\begin{array}{c}\text { concn. of } \\ \mathrm{NaCl}\end{array} & \begin{array}{c}\text { Soly. of } \\ \boldsymbol{\alpha} \text {-form }\end{array} & \begin{array}{c}\text { concn. of } \\ \mathrm{NaCl}\end{array} & \begin{array}{c}\text { Soly. of } \\ \beta \text {-form }\end{array} \\ 0 & 1.394 & 0 & 1.040 \\ 2.63 & 1.435 & 2.96 & 1.142 \\ 3.09 & 1.457 & 6.92 & 1.185 \\ 6.75 & 1.495 & 9.42 & 1.198 \\ 9.63 & 1.507 & 18.25 & 1.187 \\ 20.43 & 1.500 & 24.23 & 1.185 \\ 35.90^{*} & 1.474 * & 36.00 * & 1.184^{*}\end{array}$

2. $\mathrm{KCl}$

concn. of $\mathrm{KCl}$

Soly. of

0

$\alpha$-form

4.89

1.394

10.01

1.550

1.619

10.15

1.740

33.10

1.774

$37.48^{*}$

1. $778 *$

concn. of $\mathrm{KCl}$

0

Soly. of $\beta$-form

1.040

4.87

1.229

10.01

19.09

1.277

1.343

33.08

1.392

3. $\left(\mathrm{NH}_{4}\right)_{2} \mathrm{SO}_{4}$

$\begin{array}{ll}\text { concn. of } & \text { Soly. of } \\ \left(\mathrm{NH}_{4}\right)_{2} \mathrm{SO}_{4} & \alpha \text {-form }\end{array}$

$$
0
$$

1.394

10.87

$1.86_{3}$

19.44

$2.50_{8}$

38.95

53.40

$1.88_{7}$

$79.00^{*}$

$1.64_{4}$

$1.55_{4}^{*}$

$36.55^{*}$

1. $374 *$

concn. of Soly. of $\left(\mathrm{NH}_{4}\right)_{2} \mathrm{SO}_{4} \quad \beta$-form

$0 \quad 1.040$

$9.53 \quad 1.54_{4}$

$20.03 \quad 1.60^{4}$

$36.62 \quad 1.56_{2}$

57.80

$76.15^{*}$

1.478

$1.33_{1} *$

4. $\mathrm{NH}_{4} \mathrm{Cl}$

concn. of

$\mathrm{NH}_{4} \mathrm{Cl}$

Soly. of

concn. of

Soly. of

0

$\alpha$-form

4.86

1.394

$\mathrm{NH}_{4} \mathrm{Cl}$

$\beta$-form

1.040

4.83

1. 31

9.06

$1.40_{4}$

16.35

$1.71_{6}$

$1.92_{2}$

16.14

$1.46_{5}$

29.20

$2.28_{3}$

28.36

$1.75_{2}$

42. 20*

L-Glutamic acid in $a$-form. The same material as prepared in I was applied.

Crude L-glutamic acid in $a$-form. To the solution of crude L-glutamic acid hydrochloride which was separated from the hydrochloric acid hydrolysate of wheat gluten, caustic soda solution was added to crystallize L-glutamic acid until $\mathrm{pH}$ of the solution reached to 3.2 . The crude $a$-crystals were obtained.

Purity: $96.3 \%$ (by the enzymatic method). The contents of impurities in the crystals are exemplified in the following; L-Leu. $0.10 \%$, L-Asp. $0.18 \%$, L-Met. $0.25 \%$, humic acid $0.19 \%$.

Mother liquor of crude L-glutamic acid. The mother liquor obtained in the above preparation of crude L-glutamic acid in $a$-form.

Assay: L-Glu. 2.15\%, $\mathrm{NaCl} 20.5 \%, \mathrm{NH}_{2}-\mathrm{N} \quad 0.93 \%$, humic acid $0.16 \%$, L-Leu. $1.35 \%$, L-Asp. $0.70 \%$, L-Met. $0.35 \%$, etc.

\section{Procedure.}

The solubilities of either crude or purified crystals in water and the mother liquor of crude L-glutamic acid were measured at temperatures ranging from $30^{\circ}$ to $80^{\circ} \mathrm{C}$ according to the same procedure as in $\mathrm{I}$. The determination of the concentration of L-glutamic acid was carried out by the enzymatic method in all cases.

\section{Results.}

The results of measurement are shown in Figs. 1 and 2 .

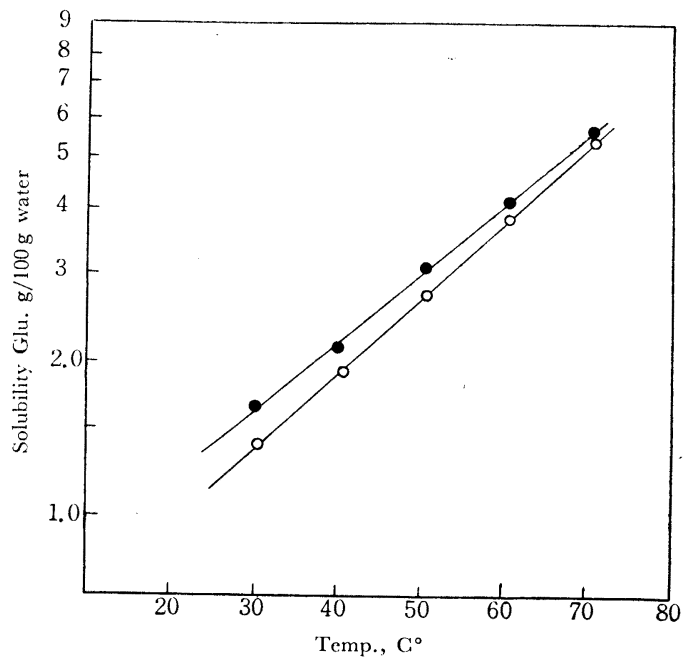

FIG. 1. Solubilities of Crude and Purified Crystals of L-Glutamic Acid in Water.

Concn. of salt and solubility are given as the amount of solute (g) per $100 \mathrm{~g}$ of water.

'Tne values with the mark* show the invariant components. 


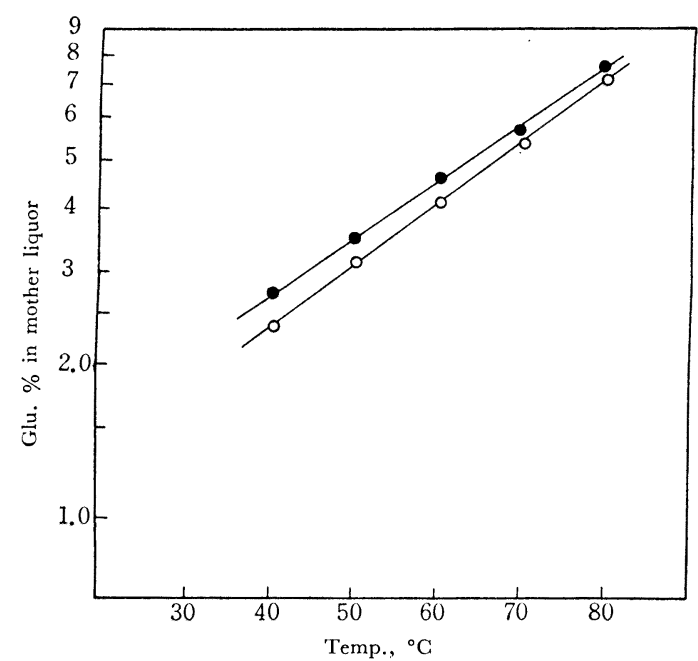

FIG. 2. Solubilities of L-Glutamic Acid in Mother Liquor of Crude L-Glutamic Acid.

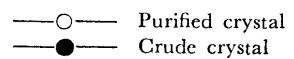

\section{DISCUSSION}

1. The influences of six amino acids on the solubility of L-glutamic acid in water were examined, when the concentrations of them were nearly same to that of L-glutamic acid, and the result has been shown in Table $I$. Histidine and valine of six amino acids applied here, showed a somewhat large solubility increasing effect, but the effect of the others could not be detected. No difference in this effect was recognized between two alternative forms of L-glutamic acid, i.e., $\alpha$ and $\beta$-forms. Takata et al. ${ }^{2)}$ had investigated the effect of amino acids mixture, which was prepared from the hyclrolyzate of wheat gluten, on the solubility of glutamic acid in water, and reported that the solubility of L-glutamic acid increased in accordance with the co-existence of the amino acids mixture. Namely, it will be sure that the solubility of $\mathrm{L}$-glutamic acid in water is raised by the coexistence of a large amount of amino acids, but the effect will be considerably small,

2) R. Takata and S. 'Tamahisa, J. Soc. Brew., Japan, 14, 565 (1936). provided that the co-existing amount is so little as in the case of this experiment.

2. Previously, Pfeiffer et al. ${ }^{3)}$ and Takata et al. reported the effect of inorganic neutral salts on the solubility of L-glutamic acid. Pfeiffer et al. recognized salting-in effects of inorganic neutral salts such as $\mathrm{LiCl}, \mathrm{KCl}$ and $\mathrm{KNO}_{3}$; on the other hand, Takata et al. concluded in their experiment that the solubility of L-glutamic acid was not influenced by the co-existence of $\mathrm{NaCl}$, when the solubility value was given as the amount of solute per unit volume of the saturated solution. But also in the latter case, the amount of solute per unit weight of solvent was raised by $\mathrm{NaCl}$. In their reports, there is no description as to the crystal form of L-glutamic acid applied, but from the values of the solubility described, it would be the $\beta$-form. In this experiment, the effects of $\mathrm{NaCl}, \mathrm{KCl}$, $\left(\mathrm{NH}_{4}\right)_{2} \mathrm{SO}_{4}$ and $\mathrm{NH}_{4} \mathrm{Cl}$ on the solubilities of L-glutamic acid in $a$ and $\beta$-forms in water were investigated, and the results were shown in Table II. The interaction between an amino acid and an inorganic salt in the aqueous solution was shown according to the following equation by Scatchard and Kirkwood ${ }^{4}$.

$$
\begin{array}{lll} 
& & -\log \gamma=\log S / S_{0}=k \Gamma \\
\text { where } & \gamma: & \text { activity coefficient } \\
& S_{0}: & \text { solubility when } \Gamma=0 \\
S: & \text { solubility at a value of } \Gamma \\
k: & \text { a coefficient } \\
\Gamma: & \text { ionic strength }
\end{array}
$$

As seen in eq. (1), logarithm of activity coefficient should be proportional not to the square root of ionic strength as in the DebyeHückel's theory, but to the ionic strength directly. Although eq. (1) can be applied only to a very diluted solution, the value of $\log S / S_{0}$ is calculated from the result in Table II and the relation between $\log S / S_{0}$ and the ionic strength is graphed on arithmetical

3) P. Pfeiffer and J. Würger, Z. Physiol. Chem., 97, 128 (1916).

4) G. Scatchard and J.G. Kirkwood, Physik. Z., 33, 297 (1932). 
scale for convenience sake, as to each salt, in Fig. 3. As shown obviously in Fig. 3, all salts applied in this experiment showed a salting-in effect on both L-glutamic acid in $\alpha$ and $\beta$-forms. Among them, the effects of two ammonium salts, i.e., $\left(\mathrm{NH}_{4}\right)_{2} \mathrm{SO}_{4}$ and $\mathrm{NH}_{4} \mathrm{Cl}$, were remarkable; on the contrary that of $\mathrm{NaCl}$ was the least. From this fact, it seems that applicability of eq. (1) or DebyeHückel equation is not so good in this experiment. It is supposed that various factors such as ionic radius, attraction between ion and solvent dipole or hydration of ion etc. participate complicatedly in this effect, in addition to the ionic strength, i.e., coulomb power, in the region of such large ionic strength as in this experiment. The values of $\log S / S_{0}$ of the $\beta$-form were always larger than that of the $a$-form. But as it cannot be considered that two alternative forms of $\mathrm{L}$ glutamic acid show different activity coefficient in the aqueous solution from each other, the other factors than the reduction of the activity due to the increase in the ionic strength will also play an important role in the increase of the solubility due to salts.

3. As one of the factors concerning the solubility at the side of solid phase, the purity of the crystal was picked up, and the solubilities of the crude and purified crystals of

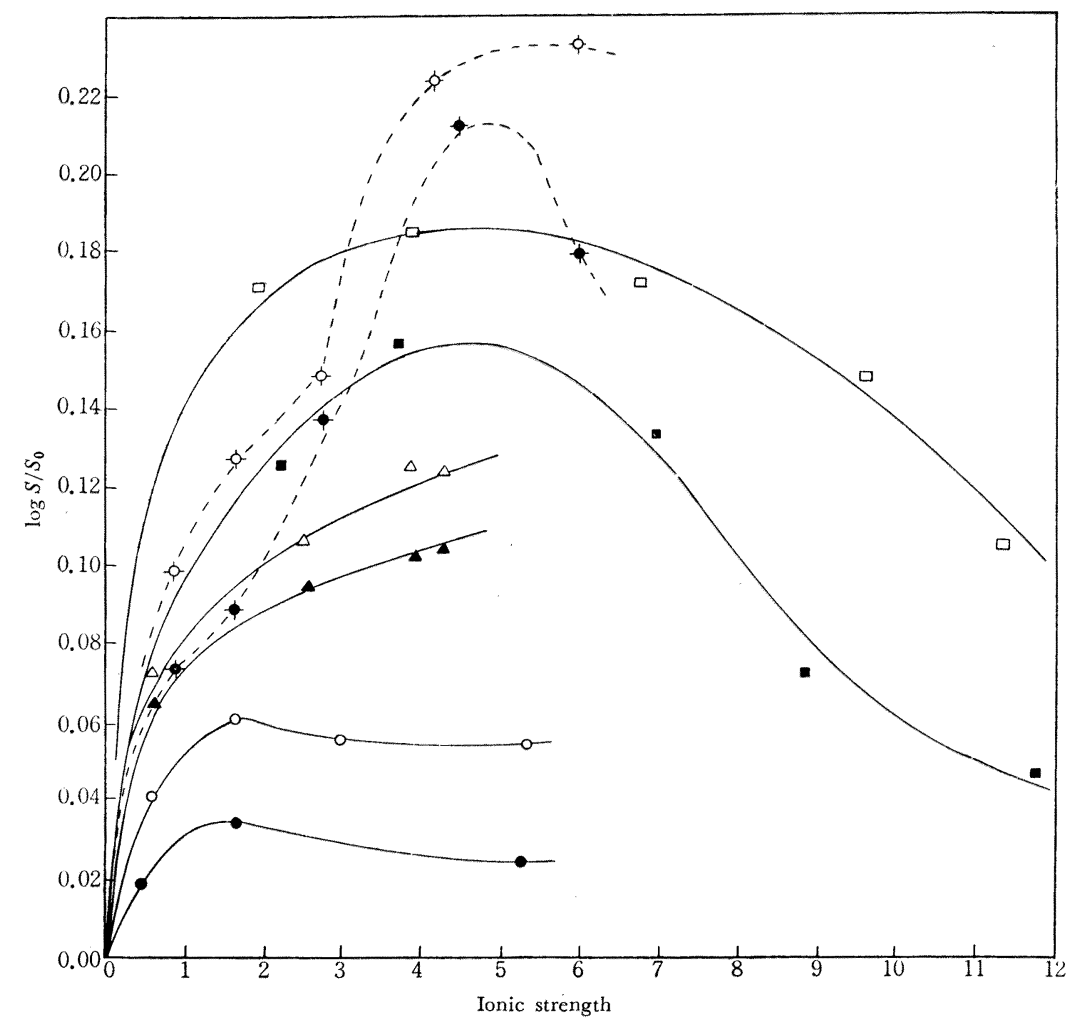

FIG. 3. $\log S / S_{0}$ vs. Ionic Strength.
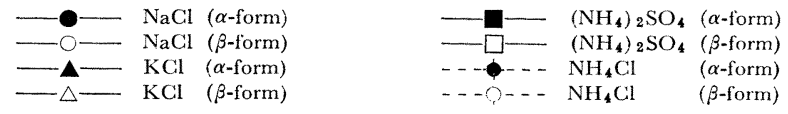
L-glutamic acid in water and in the mother liquor of crude L-glutamic acid were measured, and compared in Figs. 1 and 2. In both cases, the solubility of the crude crystals was larger than that of the purified ones. Although the crude crystals contain some quantities of impurities, amino acids mainly, as exemplified in the assay, the quantities are so little in comparison with that of in the solution that they may be neglected substan. tially, when the crystals are dissolved in the mother liquor of crude L-glutamic acid.

In measurement of the solubility in water, some portion of impurities contained in the crude crystals will dissolve into the solution, and as the result, some difference in the component of the liquid phase from the case in which the purified crystals are treated will be produced.

But the result obtained from experiment in 2 shows that impurities co-existed show practically few effect on the solubility. Therefore we concluded that the solubility difference between the crude and purified crystals recognized in this experiment is due to some difference in the condition of the solid phase between them. A close pursuit of this fact may give an important suggestion for the elucidation of the behaviors of co-existing impurities at the time of the crystallization of L-glutamic acid. In this experiment, an attempt was made to discuss what kind of difference in the condition of solid phase will influence on the solubility, when the crystal form is same. The relation between solubility and particle size is given according to the following Ostwald-Freundlich's equation.

$$
\frac{R T}{M} \ln \frac{S_{2}}{S_{1}}=\frac{2 \sigma}{\rho}\left(\frac{1}{r_{2}}-\frac{1}{r_{1}}\right)
$$

When the solute dissociates in the solution, eq- (2) is corrected by Dundon and Mack ${ }^{5}$ as follows.

\footnotetext{
5) M.L. Dundon and L. Mack, J. Am. Chem. Soc., 45, 2479, 2950 (1923).
}

$$
(1-\boldsymbol{\alpha}+n \boldsymbol{\alpha}) \frac{R T}{M} \ln \frac{S_{2}}{S_{1}}=\frac{2 \sigma}{\rho}\left(\frac{1}{r_{2}}-\frac{1}{r_{1}}\right)
$$

where $R:$ gas constant

$T$ : Absolute temperature

$M$ : Molecular weight

$S_{1}$ : solubility of a particle the size of $r_{1}$

$S_{2}: \quad \prime \prime \quad \prime \prime \quad r_{2}$

$\sigma:$ surface tension

$\rho:$ density

$\boldsymbol{\alpha}$ : degree of dissociation

$n$ : number of ions dissociated from a molecule

In a colloidal region, where each particle has a charge, the other equation was given by $\mathrm{Knap}^{6}$ ) and Kolthoff et al. ${ }^{\text {) }}$

Glutamic acid dissociates into the cation, anion and zwitterion in the aqueous solution, but as the concentration ratio of hydrogen ion to glutamic acid ion is very small, eq- (2) should be applied for glutamic acid. In eq. (2), the solubility of a particle having a sufficiently large size is put as $S_{\infty}$, and then the following equation can be obtained.

$$
\frac{R T}{M} \ln \frac{S}{S_{\infty}}=\frac{2 \sigma}{\rho} \frac{1}{r}
$$

As shown obviously in eq- (4), the solubility of a particle increases in accordance with reduction of the size, and also with increase in the surface energy.

The relations between the solubility and the particle size were hitherto studied by many investigators in regard to various substances, i.e., $\mathrm{CaSO}_{4} \cdot 2 \mathrm{H}_{2} \mathrm{O}$ by $\mathrm{Hullet}^{8)}, \mathrm{CaSO}_{4} \cdot$ $2 \mathrm{H}_{2} \mathrm{O}, \mathrm{BaSO}_{4}, \mathrm{PbI}, \mathrm{Ag}_{2} \mathrm{CrO}_{4}, \mathrm{PbF}_{2}, \mathrm{CrSO}_{4}$ and $\mathrm{CaF}_{2}$ by Dundon et al.5) They estimated the surface energy from the increase in the solubility of the finely pulverized particles according to Ostwald-Freundlich equation (2). Van Hook and Kilmartin ${ }^{9}$ recognized also the increase of $4.5 \%$ in the solubility of the very fine crystals of sucrose.

The authors ${ }^{10)}$ reported in the preceding

6) L.F. Kanp, Trans. Faraday Soc., 1 7, 457 (1922).

7) D.R. May and I.M. Kolthoff, J. Phys. Chem., 52, 836 (1948).

8) G.A. Hullet, Z. Physik. Chem., 37, 385 (1901).

9) A. Van Hook and E.J. Kilmartin, Z. Electrochem., 56, 302 (1952)

10) Y. Sakata and K. Takenouchi, 'This Journal, 25, 926 (1961). 
paper that the crude crystal of L-glutamic acid would consist of the very fine crystallites, in spite of the appearance as a single crystal, and the size of this crystallite would be an order of $1 \mu$, when the purity of the crude crystals was about $97 \%$.

We calculated the surface energy of the $a$-crystals in the aqueous solution from the results shown in Figs. 1 and 2, according to eq- (4), putting $r=1 \mu, M=147$ and $\rho=1.53$. If it is assumed that $\sigma$ is same for both the crude and purified crystals, we get about $2,000 \mathrm{erg} / \mathrm{cm}^{2}$ as the $\sigma$ value at $50^{\circ} \mathrm{C}$, and it becomes less at higher temperature, for example about $500 \mathrm{erg} / \mathrm{cm}^{2}$ at $70^{\circ} \mathrm{C}$. As these values of the surface energy are somewhat larger than the range of the value generally considered $\left(2 \sim 300 \mathrm{erg} / \mathrm{cm}^{2}\right)$, we cannot conclude that the increase in the solubility of the crude crystals of L-glutamic acid is all ascribed to the small particle size of the crystallite, of which the crude crystal consists; but this cause will surely play an important role in the increase of the solubility. Since the size of the crystallite applied in the above calculation is a very rough value, as explained in the preceding paper, it may be less in fact, and so a less value of the surface energy may be obtained, though it can be said that the size is not far smaller than $1 \mu$, because the X-ray diffraction pattern of the crude crystal does not differ from that of the purified one, without showing broad peaks. In the above consideration, it was assumed that the value of $\sigma$ is same for both the crude and purified crystals; but the $\sigma$ of the crude crystals may show a different value from that of the purified one, owing to an effect of the molecules of impurities in the crystal. In this case, the solubility increases in accordance with the increase of the surface energy.

Provided that the crystal energy increases are due to some cause, the solubility will also rise up. In a crude crystal, the arrangement of the molecules may be disturbed by adsorption of impurities on the crystal surface or in the crystal lattice, and the potential energy may increase as the result.

But the imperfection of the arrangement of the molecules cannot be so remarkable, because the X-ray diffraction patterns showed normal peaks without showing a detectable difference from that of the purified one as already explained.

Such influence of impurities on the arrangement of the molecules may be considered as one of the causes for the increase in the solubility of the crude crystals.

Furthermore, the other factors may be present in this phenomenon complicatedly.

The same tendency of the solubility as obtained here for L-glutamic acid, was recognized also for the salts of L-glutamic acid, such as the hydrochloride and the calcium salt.

Acknowledgement. The authors wish to express their sincere thanks to Mr. S. Inagawa, Managing Director of Ajinomoto Co., Inc. and Superintendent of Kawasaki Factory for his encouragement, and also to Mr. T. Fujiwara for his help in this experiment. 